\title{
Antidepressant-like effects of benzodiazepine site inverse agonists in the rat forced swim test
}

\author{
Janko Samardžić, Dragan I Obradović \\ From 18th Scientific Symposium of the Austrian Pharmacological Society (APHAR). Joint meeting with the \\ Croatian, Serbian and Slovenian Pharmacological Societies. \\ Graz, Austria. 20-21 September 2012
}

\section{Background}

There are three kinds of allosteric modulators acting through the benzodiazepine (BZ) binding site of the $\mathrm{GABA}_{\mathrm{A}}$ receptor: positive (agonist), neutral (antagonist), and negative (inverse agonist) modulators. Agonists and inverse agonists commonly exert bidirectional influences on observed behavioral parameters. In the present study we have investigated the modulation of behavioral responses to environmental novelty in two unconditioned paradigms: spontaneous locomotor activity (SLA) and forced swim test (FST), elicited by DMCM (methyl-6,7dimethoxy-4-ethyl-beta-carboline-3-carboxylate), a nonselective inverse agonist, in the dose range that previously did not produce anxiogenic effects and convulsions.

\section{Methods}

SLA in the test cage $(40 \times 25 \times 35 \mathrm{~cm})$ during 30 min was recorded automatically, beginning $20 \mathrm{~min}$ after i.p. injections (DMCM 0.1, 0.5 and $1 \mathrm{mg} / \mathrm{kg}$ ) without any habituation. FST was performed in a glass cylinder, $45 \mathrm{~cm}$ high, $20 \mathrm{~cm}$ diameter filled with water up to a height of $20 \mathrm{~cm}$, with a temperature of $21-23{ }^{\circ} \mathrm{C}$. Male Wistar rats were exposed to two swimming sessions (an initial 15-min pretest session, followed $24 \mathrm{~h}$ later by a 5 -min test session). The animals received i.p. $0.1,0.5$ and $1 \mathrm{mg} / \mathrm{kg}$ of DMCM or vehicle, $20 \mathrm{~min}$ before the test session. A rat was considered immobile whenever it floated passively in the water and only made movements necessary to keep its head above the water line.

\section{Results}

ANOVA showed a significant effect of treatment on the total immobility time of the animals during $30 \mathrm{~min}$ of monitoring of spontaneous locomotor activity $(\mathrm{p}<0.05)$. Namely, Dunnett's analysis showed that the highest applied dose of DMCM $(1 \mathrm{mg} / \mathrm{kg})$ exerted the activitydecreasing effect related to vehicle. In FST during the test session, ANOVA indicated statistically significant effects of DMCM $(p<0.05)$ on the average immobility time of animals. Dunnett's analysis showed that DMCM $(1.0 \mathrm{mg} / \mathrm{kg})$ significantly increased immoblity, but at the lowest applied dose DMCM $(0.1 \mathrm{mg} / \mathrm{kg})$ decreased immobility, and exerted acute antidepressant-like effects.

\section{Conclusions}

These data suggest that negative modulation at $\mathrm{GABA}_{\mathrm{A}}$ receptors might have triggered the acute antidepressantlike effects in rats and these effects were not confounded by locomotor influences. On the other hand, these effects are not straightforward, because they exert a kind of bimodal influence. Furthermore, these results encourage the synthesis of new BZ site ligands, aimed to possess more selective affinity/efficacy profiles.

\section{Acknowledgements}

This work was supported in part by the Ministry of Education and Science, Republic of Serbia, grant no. 175076.

Published: 17 September 2012

doi:10.1186/2050-6511-13-S1-A1

Cite this article as: Samardžić and Obradović: Antidepressant-like effects of benzodiazepine site inverse agonists in the rat forced swim test. $B M C$ Pharmacology and Toxicology 2012 13(Suppl 1):A1.

\footnotetext{
* Correspondence: jankomedico@yahoo.es

Institute of Pharmacology, Clinical Pharmacology and Toxicology, Medical

Faculty, University of Belgrade, 11129 Belgrade, Serbia
}

๑ 2012 Samardžić and Obradović; licensee BioMed Central Ltd. This is an Open Access article distributed under the terms of the 